\title{
SUJETOS POLÍTICOS Y ESTADO EN LA GEOGRAFÍA DE LAS NUEVAS TEORÍAS CRÍTICAS
}

\section{POLITICAL SUBJECTS AND STATE IN THE GEOGRAPHY OF NEW CRITICAL THEORIES}

Graciela Alejandra Inda ${ }^{1}$

Fecha de recepción: 18 de noviembre de 2017 - Fecha de aceptación: 15 de enero de 2018

\begin{abstract}
Resumen
Con el propósito de detectar las líneas de combate que suscita en el campo de intervención de las nuevas teorías críticas el problema, heredado de la tradición marxista, de la relación entre práctica política de las clases subalternas y Estado, este artículo confronta las apuestas por la multitud cooperativa y productiva, por el sujeto político como fidelidad a un acontecimiento, por el pueblo como articulación hegemónica de demandas heterogéneas y por el sujeto político como emergente de una irrupción igualitaria. Como conclusión de una lectura atenta a las operaciones de demarcación y a las confluencias, se reconoce el trazado de divisorias de aguas no superpuestas: entre las posiciones que, más allá de sus diferencias, definen a la política (y a sus sujetos) como una práctica excepcional en la historia de las formas de dominación que sólo adquiere todo su espesor cuando se despliega por completo a distancia del Estado y una posición que inscribe la política y sus operaciones en el campo estratégico del Estado; entre una visión de la política como espacio que se designa a sí mismo y crea sus propios sujetos (o es creada por ellos) y una perspectiva para la cual el mundo de la producción es el único terreno en el que puede conformarse un sujeto político auténtico; entre una tendencia que reclama por el internacionalismo de las luchas populares o de la multitud y otra que sitúa a los sujetos políticos en los espacios nacionales.
\end{abstract}

Palabras claves: Teoría política; marxismo; clase social; Estado nacional; Hegemonía cultural

\begin{abstract}
This article attempts to elucidate the lines of combat in the field of New critical theories, around the problem -inherited from Marxist tradition- of relationship between: political practice of subaltern classes and State. In attention to that, the bets of different positions -such as cooperative and productive multitude; the political subject as loyalty to the event; the people as hegemonic articulation of heterogeneous demands and the political subject as emerging of an egalitarian irruption-are confronted. As conclusion of a reading committed to demarcation operations and confluences, the text recognizes the delineation of non-overlapping watersheds: between positions that, beyond their differences, define politics (and its subjects) as an exceptional practice in the history of forms of domination, fully deployed outside the State; and a position that inscribes politics and its operations inside the strategic field of the State; between a vision of politics as a place that designate itself and creates its owns subjects (or is created by them) and a perspective which conceive that the world of production is the only field where an authentic political subject can be constitute; between a tendency claiming for internationalism of popular struggles or multitude and another one placing political subjects into nationals spaces.
\end{abstract}

Key Words: Political theory; Marxism; Social class; National state; Cultural hegemony

1 IMESC/IDEHESI/CONICET y Facultad de Ciencias Políticas, UNCuyo, Argentina, gracielainda@hotmail.com 


\section{Introducción}

La preocupación por las relaciones entre movimiento obrero o movimiento de masas y Estado, planteada con insistencia teórica y urgencia política por la tradición marxista clásica ${ }^{2}$, reaparece en las nuevas teorías críticas, como llama Keucheyan (2013) al conjunto diverso de empresas que desde fines de los noventa reflexionan sobre el orden capitalista y sus formas de sujeción sin dejar de interrogarse por las condiciones de un proceso emancipatorio.

Pero si la pregunta viene de lejos, las respuestas traen ropajes nuevos. Mientras que los marxistas de comienzos del siglo XX confiaban en la capacidad de las organizaciones obreras, en las que muchas veces militaban, para transformar el orden capitalista, buena parte de la cartografía crítica contemporánea ${ }^{3}$, colocada bajo el signo de la derrota de los grandes movimientos populares ${ }^{4}$ de los sesenta y setenta, está convencida de la ausencia de un sujeto de la emancipación claramente identificado con una clase y se adjudica la tarea de pensar la transformación social en nuevos términos.

Formada en el espacio de discusión abierto por la crisis de la tradición comunista, en el curso de la cual campean las denuncias contra la insuficiencia teórica del discurso marxista sobre la política y el Estado, una franja importante de las teorías críticas que entra en escena tras la caída del Muro de Berlín se desmarca de la concepción leninista del poder concentrado en el Estado, de la concomitante estrategia de una lucha frontal en una situación de doble poder y también de la fórmula del partido de la clase obrera como aglutinante privilegiado para la transformación histórica.

Las apuestas teóricas por la multitud cooperativa y productiva (Hardt y Negri), por el sujeto político como fidelidad a un acontecimiento (Badiou), por el pueblo como articulación hegemónica de demandas heterogéneas (Laclau y Mouffe), por el sujeto político como emergente de una irrupción igualitaria (Rancière) forman parte de esa tendencia que busca identificar las nuevas subjetividades o las articulaciones múltiples que vinieron a desplazar la centralidad política de la clase obrera en las condiciones actuales del capitalismo. De esta manera, contra las tesis posmodernas que anuncian el fin de la política, buscan rescatar el potencial de la práctica política y de sus sujetos ${ }^{5}$, y al mismo tiempo, tomar distancia de la que consideran la ortodoxia esencialista.

Ahora bien, por encima de ese común denominador, las teorías alternativas al proyecto marxista arriba mencionadas, todas de gran impacto y resonancia en las últimas décadas, mantienen entre sí diferencias y discusiones de peso, entre las cuales el problema del vínculo entre práctica política, sujeto político y Estado ocupa un lugar destacado ${ }^{6}$.

En concreto, este artículo busca identificar las herramientas conceptuales y las tesis que ponen en escena esas teorías críticas al enfrentar los siguientes dos interrogantes heredados de la tradición

2 En un texto conocido, Anderson (1985) observa que mientras los problemas organizativos y tácticos de la lucha de clases y los análisis sobre la maquinaria del Estado capitalista ocupaban un lugar central en la reflexión de las primeras generaciones de marxistas (Lenin, Luxemburgo, Kautsky, Bujarin, Trosky, entre otros), dando lugar a encendidos debates, el marxismo occidental, desplegado entre los años 20 y los sucesos del 68, se caracterizó, con la excepción de Gramsci, por el abandono de estos temas y el viraje hacia la filosofía, la epistemología y el lenguaje.

3 La expresión "cartografía" ("geografía” o "mapa”) referida a las denominadas nuevas teorías críticas pretende subrayar el interés por trazar en ese conjunto heterogéneo ubicaciones y posiciones relevantes.

4 Keucheyan (2013) señala con acierto que de la misma manera que el marxismo occidental debe analizarse a partir de las derrotas que sufre el movimiento obrero alemán hacia 1920 y de las derivas del régimen soviético, sólo es posible comprender la naturaleza de los pensamientos críticos contemporáneos considerando que son emergentes de un largo proceso de derrota de los proyectos de izquierda que culmina con la caída del Muro de Berlín.

5 Balibar (2005) indica que toda concepción de la política implica una concepción del sujeto, en cada caso específico.

6 De hecho, pueden encontrarse referencias mutuas a lo largo de sus escritos, textos y entrevistas en los que discuten explícitamente entre sí e incluso debates cara a cara en coloquios y seminarios; los cuales serán tenidos aquí en cuenta en función de su pertinencia respecto de la indagación propuesta. 
marxista clásica y de los debates sobre las relaciones partido/Estado de los sesenta y setenta. En primer lugar, los sujetos políticos ¿se configuran según una trama mundializada o se constituyen y movilizan en el terreno local y nacional? (el dilema nacionalismo/internacionalismo). En segundo lugar, ¿qué tipo de relación de la práctica política con el Estado y sus aparatos torna viable un proceso de transformación de las condiciones de vida de la mayorías?, ¿es posible que las fuerzas populares o las luchas de la multitud construyan poder efectivo en el campo del Estado o están resignadas a quedar entrampadas en su esquema de dominación?, ¿es la democracia liberal un terreno propicio para prácticas políticas emancipadoras o se encuentra totalmente al servicio de la acumulación del capital? (el dilema estatismo/anti-estatismo).

Sin desconocer los aportes realizados por estudios previos, mayormente orientados por preocupaciones filosóficas (Muñoz, 2006; Marchart, 2009; Fair, 2010; González Canosa, 2011; Camargo, 2014; Harrison, 2016; Guille, 2017; entre otros), la ambición última de este trabajo consiste en detectar las líneas de combate que suscita en la geografía de las nuevas teorías críticas el viejo problema de la relación entre la práctica política de las clases subalternas y el Estado.

\section{1- La cuestión nacional/global}

Como es bastante conocido, Hardt y Negri (2002a) sostienen que a partir del derrumbe de los regímenes coloniales y de la caída de las barreras interpuestas por el bloque soviético al mercado mundial se produce la conformación de un imperio cualitativamente diferente del viejo imperialismo basado en la expansión territorial de los Estados nacionales. La nueva forma de soberanía imperial, que se presenta flexible, móvil y transgresora de todas las fronteras y límites, da forma a un mundo descentrado, en el que ninguna potencia se impone definitivamente.

Los Estados-nación no pueden ya pretender cumplir el rol de autoridad última como en la época de la modernidad, puesto que esa autoridad, vinculada a las grandes multinacionales y sus organismos, se localiza en el Imperio y los sobrepasa (Hardt y Negri, 2002b).

En las nuevas condiciones si bien los Estados conservan funciones importantes, tales como asegurar los esquemas jurídicos, administrativos y monetarios necesarios al flujo internacional del capital y poner en marcha los dispositivos represivos y disciplinarios locales de contención de las luchas de los trabajadores, las mismas no se orientan según los intereses nacionales o regionales sino cada vez más según las necesidades del poder imperial (Hardt y Negri, 2004).

Entonces, como forma de resistencia al poder global, ¿hay que pensar y valorizar estrategias y sujetos políticos que apunten a una recuperación de las soberanías nacionales? Hardt y Negri responden negativamente.

Las luchas contra el imperio sólo pueden ser llevadas adelante por un sujeto igualmente descentrado y global que supere las divisiones entre las masas del planeta según los corsés de las identidades nacionales. Sólo una fuerza de trabajo que se mueva por medio de rutas de emigración, que practique el nomadismo, el mestizaje y el éxodo puede hacer trastabillar la estructura temible del imperio (Hardt y Negri, 2002a).

Todas las formas de trabajo socialmente productivas subordinadas al gobierno del capital a lo largo del globo, desde las formas industriales, agrícolas y mineras hasta las afectivas e intelectuales, se comunican, colaboran e integran lo común, conformando así una multitud que trasciende las fronteras y se encuentra dotada de la capacidad de construir en forma autónoma una alternativa al poder imperial ${ }^{7}$ (Hardt y Negri, 2002a; 2004).

7 El concepto de multitud se apoya en la hipótesis, desarrollada desde Imperio en adelante en numerosos textos, según la cual la producción moderna, caracterizada por la hegemonía del trabajo industrial, ha sido desplazada por la informatización y la posmodernización de la producción que coloca en primer plano las formas de trabajo intelectual caracterizadas por la cooperación y la comunicación. En esta era posmoderna se torna cada vez más difícil diferenciar el trabajo productivo del trabajo improductivo y definirlo en términos estrictamente económicos porque todo trabajo (material e inmaterial, intelectual o corporal) produce y reproduce bienes materiales, comunicación, relaciones y formas de vida, y en el proceso sufre la explotación del capital. 
Este nuevo proletariado, emergente de la producción posmoderna, no reconoce una clase productiva que tenga prioridad sobre las demás clases explotadas. Todas las formas de trabajo son igualmente productivas y “(...) comparten también el potencial común de oponer resistencia a la dominación del capital” (Hardt y Negri, 2004, p. 135).

La conformación de la multitud como un sujeto político, esto es, con capacidad de tomar decisiones y actuar en común, depende de la comunicación a través del tiempo y del espacio de los múltiples movimientos y resistencias. Sólo mediante la intensificación de cada una de las luchas locales y su articulación con otras nuevas, en un plano que sólo puede ser mundial, puede construirse un poder constituyente opuesto al imperio (Hardt y Negri, 2004; Hardt, 2012).

Toda fórmula de liberación nacional produce una movilización de las fuerzas populares que no sólo resulta impotente ante la estructura del poder global sino que termina encauzada por el poder del Estado nacional. No hay forma de que las clases populares logren construir poder propio desde las instituciones del Estado nacional, ni siquiera en la periferia, pues la vida política queda subsumida en el cuerpo estatal (Hardt y Negri, 2002a).

Oponiéndose al diagnóstico de una nueva era caracterizada por la desimperialización y la descentralización del poder económico, Badiou entiende que lejos de conformar un fenómeno reciente y específico de nuestros tiempos la mundialización es coetánea e inseparable del capitalismo. Lo que presenciamos desde hace décadas -sugiere- es el retorno de la acumulación primitiva del capital en una magnitud antes restringida por la alternativa comunista que bloqueaba la ampliación del mercado mundial (Badiou y Gauchet, 2015).

El imperialismo sólo ha cambiado de forma. Al colonialismo del reparto le ha seguido una anarquía de la zonificación, esto es, una estrategia de saqueo generalizado mediante la creación de enclaves monopólicos de riquezas locales estratégicas que aprovecha la debilidad de los Estados y contribuye a ella. Pero cuidado -advierte-, la actual mundialización no debe identificarse con una supuesta era posestatal en la cual se habría producido una nivelación global de los actores con poder de decisión: los Estados Unidos siguen siendo el centro sistémico del capitalismo mundial (Badiou y Gauchet, 2015).

Si el diagnóstico contiene diferencias sustanciales (nueva forma de soberanía desterritorializada vs. imperialismo de la zonificación), al igual que sus concepciones del sujeto político, coinciden estos representantes de la denominada izquierda radical en un punto clave: la emancipación sólo puede ser global.

Partiendo de reconocer que el mundo del capitalismo y de las democracias ricas es en realidad un falso mundo, que sólo reconoce la unidad de los productos y los signos monetarios mientras arroja a la mayoría de la humanidad a "otro" mundo devaluado, del que se separa mediante murallas y guerras, Badiou (2008b, p. 65) entiende que afirmar que "hay un solo mundo" constituye un principio de acción, un imperativo político por la igualdad de las existencias, que no contradice el juego infinito de las identidades y las diferencias.

Desde su perspectiva, sólo el internacionalismo, entendido como una conjunción de iniciativas contra la mundialización (que pueden provenir, aunque es imposible saberlo con certeza, de las resistencias militantes de la juventud universitaria crítica, de la juventud popular, del proletariado nómade y del proletariado precarizado), lograría evitar el callejón sin salida de un movimiento popular que al no vincularse con otros termina sirviendo al capital globalizado.

La escala real de la construcción política es mundial. La hipótesis comunista debe verificarse, desde luego, a través de los movimientos populares locales. Pero en lo que se refiere a su visión de conjunto, a su espacio de experimentación, de fracaso o de éxito, abarca y afecta la totalidad del mundo. Cuando uno tiene un adversario, debe tratar de ponerse a su altura, y el capitalismo es una fuerza mundial. (Badiou y Gauchet, 2015, p. 163)

Los proletarios, hoy más nómadas que nunca, no tienen patria y constituyen el cuerpo vivo del internacionalismo. Hay que desconfiar de la palabra pueblo cuando va seguida de un adjetivo que define 
una identidad nacional ${ }^{8}$ puesto que constituye una categoría del Estado que designa el conjunto inerte de los que tienen derecho de decirse pueblo, frente a otros que quedan excluidos (Badiou, 2014).

La capacidad de convertirse en sujeto político no proviene para este pensador francés de los pliegues del mundo de la producción sino que implica el reconocimiento por parte del sujeto (el militante, por ejemplo) de un acontecimiento que es por definición imprevisto y revulsivo de la coacción colectiva existente y del complejo capitalista ${ }^{9}$. Más aún, el acontecimiento político auténtico exige la experimentación de la hipótesis comunista como única vía contra la despolitización profunda del capitalismo. El sujeto político es así portador de un axioma igualitario y de una aspiración de emancipación anticapitalista (Badiou, 1999; Badiou y Gauchet, 2015).

Por otra parte, mientras Hardt y Negri hacen foco en la propagación geográfica de los movimientos anticapitalistas, en la comunicación por contagio, Badiou entiende que "(...) una suma de rebeliones no hace ningún sujeto" (2008a, p. 68) y reclama una instancia de organización orientada en el ideario comunista que desborde el esquema partidista y se encuentre inmersa en la sociedad.

Rancière (1996) concede que actualmente el poder estatal no sólo es impotente frente a la necesidad mundial del capital que lo domina sino que funda su legitimidad en esta ausencia de elección. El Estado ya no oculta su dependencia del capital global sino que fundamenta su autoridad en su capacidad de gestionar la crisis inevitable, esto es, en su poder para evitar un escenario de miseria amenazante y caos.

Pero también observa que la constitución (siempre a distancia del Estado) de un pueblo como subjetivación colectiva no es ajena al espacio nacional, pues la política conlleva la construcción local y singular de casos de universalidad (Rancière, 1996). Si bien el capital es un poder mundial, las simbolizaciones igualitarias y abiertas que permiten la configuración de un sujeto político actúan sobre puntos de emergencia locales y se refieren a una dominación que se ejerce en un espacio nacional. La nación no deja de ser una simbolización colectiva conformada como un campo de lucha permanente (Rancière, 2016).

El sujeto político de Rancière (1996) no se refiere al desarrollo de una esencia, ni de clase ni de nacionalidad, ni es la encarnación de una meta, sino que se refiere a modos de subjetivación que reclaman mediante actos de enunciación un principio igualitario donde no lo hay. La política no expresa un sujeto latente, como en el esquema de la multitud, sino que surge cuando aparece un grupo que no había sido tomado en cuenta y busca construir un nosotros abierto a cualquiera, sin importar su pertenencia social. El pueblo como modo de subjetivación emerge -tal como en Badiou- de un acto político que choca contra el orden social establecido e intenta inventar un cuerpo nuevo.

Los teóricos del populismo Laclau y Mouffe no sólo piensan la construcción de los sujetos políticos en el marco de los Estados nacionales sino que además sostienen que la democracia liberal y nacional lejos de ser el enemigo a derrotar conforma el terreno histórico de emergencia de las luchas colectivas encaminadas a luchar contra las desigualdades y a poner en cuestión las relaciones de subordinación ${ }^{10}$.

Incluso admiten que en ciertas condiciones los sujetos políticos pueden construirse a partir de la acción de los Estados nacionales. Los movimientos populistas que surgen en América Latina, tras la crisis del treinta, por ejemplo, se desarrollan -señala Laclau (2007) - esencialmente como populismos de Estado, esto es, a partir de la intervención de un Estado nacional fuerte que se opone al poder oligárquico.

8 La excepción -sugiere- está dada por las guerras de liberación nacional, en las cuales, de manera transitoria, la expresión pueblo nacional puede tener un sentido positivo.

9 El sujeto fiel y el acontecimiento son igualmente originarios, ninguno puede darse sin el otro, pues el acontecimiento requiere ser nombrado por el sujeto y el sujeto nace a sí mismo en un proceso colectivo capaz de determinar una visión común (Badiou, 1999).

10 Partiendo de la tesis de la pluralidad e indeterminación de lo social, estos autores afirman que la lucha contra la subordinación no puede ser resultado de la propia subordinación. Corresponde a la acción política la tarea de transformar una relación de subordinación en una relación de opresión, sede de un antagonismo. Y no hay relación de opresión sin la presencia de un exterior discursivo a partir del cual la subordinación puede ser interrumpida (Laclau y Mouffe, 2015). 
La cualidad más distintiva del capitalismo globalizado como nuevo estadio en la historia del capitalismo no reside en el desvanecimiento de la soberanía de los Estados nacionales sino en la multiplicación de los efectos dislocatorios y la proliferación de nuevos antagonismos, proceso que impone a todo movimiento político antiglobalización las tareas de construcción de vínculos equivalenciales entre demandas sociales heterogéneas y la producción de un lenguaje común (Laclau, 2007).

No existe una lucha anticapitalista per se sino más bien efectos anticapitalistas que pueden derivar, en cierto punto de ruptura, de la articulación de una pluralidad de luchas. Lo que hay que preguntarse, afirma Laclau (2007), es si el anticapitalismo global conforma (o no) un significante vacío que contribuye a la unificación del campo de equivalencias anticapitalistas.

Contra la idea de una multitud dotada de una tendencia natural a la resistencia y cuya unidad “(...) proviene de la agregación espontánea de una pluralidad de acciones que no necesitan de una articulación entre ellas mismas" (Laclau, 2008, p. 129), la construcción de un pueblo es valorada como la operación política por excelencia.

Operación que resulta de una práctica político-discursiva articulatoria de demandas heterogéneas en torno de un significante vacío, que al carecer de toda base social o ideológica previa a su despliegue autónomo, es por naturaleza imprecisa y fluctuante. En tanto efecto de una lógica política, el pueblo no conforma necesariamente un vector de emancipación sino que bien puede, en tal o cual coyuntura, designar un sujeto político reaccionario.

En ese punto preciso, Laclau polemiza con Rancière. Si bien aprecia su definición del pueblo como irrupción político/discursiva de una declaración igualitaria, estima que

(...) identifica demasiado la posibilidad de la política con la posibilidad de una política emancipatoria, sin tomar en cuenta otras alternativas; es decir, la posibilidad de que los incontados construyan su incontabilidad en formas que son ideológicamente incompatibles con aquello que Rancière o yo podríamos defender políticamente (por ejemplo, en una dirección fascista). (2007, p. 306)

\section{2- La cuestión de la autonomía}

Contra la idea de que la dominación se encarna privilegiadamente en el Estado, Laclau y Mouffe (2015) sostienen que la sociedad civil también es sede de relaciones de opresión. Más aún, el Estado puede llevar adelante, muchas veces contra la sociedad civil, políticas que combaten formas de desigualdad (por ejemplo, la legislación por la igualdad de género). En los países periféricos, la expansión de las funciones del Estado central puede incluso conformar un medio contra formas extremas de explotación por parte de las oligarquías.

Como ya se observó, es perfectamente posible en este esquema teórico que la construcción de un pueblo comience a nivel del Estado. El actual proceso boliviano es un ejemplo de populismo de Estado, esto es, de un proceso de movilización popular en torno de una serie de demandas insatisfechas impulsada en un principio por el Estado (Laclau, 2008).

Salvo que se fomente la impotencia política, no puede haber una exterioridad total entre movimientos de lucha y Estado. De lo que se trata es de "(...) estar con un pie adentro y un pie afuera del sistema" (Laclau, 2009, p. 816), evitando tanto la nulidad política que conlleva la esperanza en la sola acumulación espontánea de las resistencias como la completa absorción institucional que conduce al estancamiento.

En contraposición, encontramos en Badiou un anti-estatismo virulento: “(...) todo Estado tiene una dimensión criminal intrínseca, porque todo Estado es una mezcla de violencia e inercia conservadora” (Badiou y Gauchet, 2015, p. 75). En consecuencia, “(...) toda política digna de ese nombre debe marcar necesariamente su desacuerdo, su independencia de principio con respecto a las diversas formas de omnipotencia y persistencia estatales" (Badiou y Gauchet, 2015, p. 75-76). En otros términos, la política no es un medio para la toma del poder de Estado, sino que, cuando tiene lugar, existe por ella misma (Badiou, 2003). 
Rancière (1996; 1997) también se alinea decididamente entre las posturas antiestatistas. Si bien reconoce que un orden policial (término que reserva para las actividades estatales) que proporciona beneficios a los ciudadanos es preferible a otro que no lo haga, esto no cambia su naturaleza, esto es, constituir un conjunto de mecanismos que distribuye los lugares y las funciones de los grupos y organiza el consentimiento. La política, como en Badiou, no consiste en el ejercicio del poder sino en la manifestación del disenso y su tarea esencial es la configuración de su propio espacio y la visibilización de sus sujetos.

Los derechos y libertades que se registran en el campo del Estado no son el efecto de la ciencia de los legisladores o de la gestión estatal sino de las fracturas producidas por la lógica igualitaria en ellos (Rancière, 1996). El principio igualitario por el que se define la política siempre se constituye como provocación al principio estatal confiscador del poder colectivo. Hay que defender -reclama en debate con el defensor del populismo- la autonomía de los movimientos respecto de las organizaciones partidarias y sindicales y del sistema estatal (Rancière y Laclau, 2015).

En diferentes intervenciones, Hardt y Negri sostienen que el Estado, aunque en retroceso frente al poder económico transnacional, sigue teniendo a cargo un proceso decisivo para la contención y el aislamiento de las luchas de resistencia: la transformación de la multitud, mediante la sujeción y la represión, en un pueblo regulado y controlado.

El pueblo depositario de la soberanía constituye para ellos una construcción ilusoria realizada por las instituciones representativas, entre las que se destaca el proceso electoral, que tiene por objetivo convertir la multiplicidad empírica de la población en una identidad que sirva a la acumulación capitalista (Hardt y Negri, 2002b). A diferencia de la multitud, caracterizada por la diversidad y por la comunicación entre modos de vida singulares, el pueblo gestionado por el Estado es una figura unitaria y homogénea que no deja espacio a las diferencias internas (Hardt y Negri, 2004).

Negri (2001a) afirma que el contrapoder de la multitud y el poder constituido del imperio no son homologables y que es necesario que la estrategia de contrapoder no tenga como objetivo hacerse con el poder sino desarrollar una nueva potencia de vida, de organización y de producción. Dotada de la capacidad de oponerse al imperio sin intermediarios, la multitud busca construir un contrapoder por fuera de las fuerzas del Estado y del capital. ¿Bajo qué formas, siguiendo qué estrategias? Sólo las experiencias concretas de luchas -admite Negri (2001b)- van a poder indicar cuál es el instrumento a construir y el camino a recorrer.

Frente a la ambición neoliberal de privatización de la naturaleza y de los resultados de la producción social, la gestión y la regulación estatal no constituyen una verdadera alternativa. De lo que se trata es de construir un concepto de privacidad que en lugar de la propiedad privada exprese la singularidad de las subjetividades sociales y un concepto de lo público basado en lo común (Hardt y Negri, 2004; 2009).

\section{3- La cuestión capitalismo/democracia}

Como es conocido, Laclau y Mouffe afirman que la política de izquierda debe hacerse cargo de las reivindicaciones inauguradas por la revolución francesa. Ante la ofensiva de la nueva derecha, que en nombre de una concepción negativa e individualista de la libertad pone en jaque el principio según el cual se precisa de la intervención del Estado para luchar contra las desigualdades sociales, una alternativa de izquierda sólo puede consistir en “(...) ubicarse plenamente en el campo de la revolución democrática y expandir las cadenas de equivalencias entre las distintas luchas contra la opresión” (Laclau y Mouffe, 2015, p. 222).

Una política para la emancipación no puede ignorar que lo valioso de la democracia liberal moderna radica en que constituye un espacio en el cual la confrontación entre diversas interpretaciones 
de los principios de igualdad y libertad se mantiene abierta y las relaciones de poder están siempre en cuestión ${ }^{11}$ (Mouffe, 2012).

La revolución -insisten- entendida como momento fundacional, como punto de concentración del poder a partir del cual la sociedad puede ser transformada debe ser abandonado. De la desaparición de la propiedad privada de los medios de producción no se sigue necesariamente la extinción de toda forma de subordinación, pues no hay nexos esenciales entre las distintas luchas. Una estrategia democrática por el poder necesita de una práctica equivalencial entre las diferentes luchas de manera que la defensa de los intereses de los obreros, por ejemplo, no se haga a costa de los derechos de las mujeres, de los inmigrantes, de los consumidores, etc. Requiere asimismo, para dar lugar a la pluralidad y al respeto por la esfera individual, que esta demanda de igualdad sea balanceada con la demanda de libertad. El objetivo es un movimiento democrático con reconocimiento tanto de la multiplicidad como de la necesidad de una articulación política incesante (Laclau y Mouffe, 2015).

Frente a los que defienden sus posibilidades, Badiou sostiene que en la medida en que la esencia de la democracia reside en la competencia individual y en la atomización del sujeto político, que queda identificado con el sujeto comprador-vendedor del mercado, es incapaz de propiciar o permitir espacios que generen oposiciones serias al capital (Badiou y Gauchet, 2015).

Si el espacio estatal sólo deja a los ciudadanos el derecho de voto, la democracia parlamentaria no puede ser la vía para practicar una política de emancipación (Badiou, 2008b). Toda impugnación radical de la autoridad del capital pasa entonces por un cuestionamiento drástico del pluralismo democrático que no es sino un pluralismo de las pequeñas diferencias toleradas por el capital (Badiou y Gauchet, 2015).

Esto no significa para Badiou que haya que abandonar la palabra democracia sino que hay que luchar por despegarla de su malversación capitalista y por reconocer su verdadera naturaleza como igualdad ante la Idea política (2008b). El comunismo, contrario a todo proyecto democrático representativo, es la única buena hipótesis para pensar una política de la emancipación. "Quienquiera que abandona esta hipótesis se resigna, en ese mismo momento, a la economía de mercado, a la democracia parlamentaria (la forma de Estado apropiada para el capitalismo) y al carácter inevitable y natural de las desigualdades más monstruosas" (Badiou, 2008b, p. 97).

Rancière (1996), como Badiou, considera que la forma de democracia vigente en las sociedades contemporáneas, a la que denomina democracia consensual o posdemocracia, se caracteriza por su identificación absoluta con la gestión del capital y por conformar un régimen que produce la liquidación del pueblo como sujeto político perturbador.

En discusión con Laclau, para quien el principio de representación puede funcionar en ciertas coyunturas como una instancia que permite la constitución de una voluntad a partir de sectores marginales con escaso ímpetu propio y como antídoto contra la dispersión propia de formas de democracia anárquicas, sostiene que en las posdemocracias este principio está casi vacío, pues se encuentra privatizado por los poderes económicos y absorbido por el Estado (Rancière y Laclau, 2015). La democracia no es un conjunto de instituciones (Estado de derecho) ni un tipo de régimen entre otros (régimen parlamentario) ni tampoco es un estado de lo social (el reino del individualismo o de las masas) sino que es "(...) una manera de ser de lo político que se hace patente en las formas de existencia autónoma del pueblo" (Rancière, 1996, p. 125).

Hardt y Negri se suman de buen grado a la crítica de las democracias existentes, pues -como se mencionó- consideran que sus mecanismos de representación conducen a la producción de un pueblo

11 A partir de la distinción entre "lo político" como la dimensión de antagonismo, conflicto y hostilidad que es inherente a las relaciones humanas y "la política" como la práctica que apunta a organizar las relaciones humanas en las condiciones siempre conflictivas derivadas de lo político (Mouffe, 1999; 2011), sostiene que la democracia (a la que denomina "agonística") exige la aceptación de su carácter inevitablemente conflictivo y el abandono de toda pretensión de un consenso sin exclusión. 
Uno. Pero hay algo más. Esta democracia no sólo se encuentra limitada a funcionar como un momento de selección del miembro de la clase dominante que va a representar ilusoriamente al pueblo sino que se ha tornado irrealizable. El poder imperial y sus instituciones económicas supranacionales funcionan cada vez más completamente al margen de los mecanismos de representación popular y obstaculizan la definición de espacios políticos nacionales en los que sea posible representar al pueblo como soberano (Hardt y Negri, 2002b).

Esa crisis actual de la democracia -indican- es reconocida y denunciada por las multitudinarias protestas contra la globalización que en su diversidad reclaman una participación efectiva y una democracia construida desde abajo, resistiéndose a la corrupción de la democracia como rostro político del capitalismo o régimen de las élites burocráticas (Hardt y Negri, 2004).

De todas maneras, su planteo no es pesimista. La relación política de la soberanía se parece cada día más -aseguran- a la relación económica entre capital y trabajo, pues de la misma manera que el capital depende de la productividad del trabajo, la soberanía imperial precisa del consentimiento y de la productividad social de los gobernados. Los gobernados, aunque explotados, no pueden ser excluidos, pues si rechazaran la relación de poder el imperio se derrumbaría como un cuerpo sin vida (Hardt y Negri, 2004).

La salida no pasa por la vuelta al socialismo, al que consideran obsoleto (Negri, 2007), sino por la búsqueda de nuevas formas de democracia que no sean representativas o que bien impliquen nuevas formas de representación acordes a la multiplicidad de la multitud (Hardt y Negri, 2002b). En concreto, no dudan en reivindicar la práctica y la teoría comunistas como movimiento de crítica radical de todo lo existente. A contramano de sus apropiaciones indebidas, Hardt (2012) entiende el comunismo no como la exaltación del Estado sino como su abolición, no como supresión del disenso político y de la libertad de expresión sino como experimentación de formas de libertad y participación democrática inéditas en las sociedades contemporáneas.

\section{Conclusiones}

Si bien sus propuestas de base contienen fuertes contrastes, los teóricos de la multitud coinciden con Badiou y Ranciére en una posición esencial del "campo de batalla" en que intervienen las nuevas teorías críticas: la práctica política, identificada de lleno con el horizonte de una ruptura emancipatoria, sólo tiene lugar allí donde se despliega por completo a distancia de los aparatos e instituciones del Estado.

Definida en función de la hipótesis comunista y de naturaleza excepcional, la política de Badiou es lo contrario del orden estatal siempre abocado a producir con sus aparatos barreras que frenen las diversas iniciativas igualitarias contra la privatización capitalista. Los movimientos de masas y las organizaciones populares no pueden -sugiere- quedar entrampados en los falsos mecanismos de participación que ofrecen las democracias parlamentarias actuales, regidas por la ideología del individualismo y constitutivamente colocadas bajo la autoridad del capital.

También para Rancière la política está en las antípodas del Estado, puesto que su ocurrencia, bajo la forma de un accidente recurrente, depende de unos sujetos que ponen en marcha un reclamo igualitario y disruptivo que viene a suspender las divisiones consagradas por el orden estatal. Si bien los movimientos populares pueden realizar inscripciones igualitarias en las instituciones y en las leyes, estos efectos sólo tienen un carácter parcial a la vez que quedan expuestos a su regulación y neutralización. Sólo si actúan como fuerzas autónomas respecto de los mecanismos y las instituciones de la posdemocracia, siempre interesadas en coartar toda irrupción conmovedora, pueden esos movimientos generar un "nosotros" abierto a cualquiera.

En sintonía, Hardt y Negri consideran que la única salida emancipatoria pasa por una acción completamente autónoma de la multitud, ya que cuando la lucha se institucionaliza, cuando es canalizada en partidos o sindicatos, cuando queda enmarcada en la figura de un pueblo a representar, el capital 
y el Estado comienzan a usarla en su propio beneficio. Con su potencia constituyente, la revolución del común daría lugar a formas de democracia que, a diferencia de las democracias actuales capturadas por el capital imperial y las burocracias, no requerirán de líderes ni de instituciones representativas.

Como telón de fondo de esta posición compartida, una concepción del Estado -que ciertamente recuerda la concepción marxista leninista- como maquinaria represiva e ideológica al servicio de la dominación del capital. La diferencia con el planteo leninista radica, claro está, en que ya no se trata de reunir fuerzas para atacar la fortaleza estatal sino de construir alternativas de contrapoder que le sean foráneas, que habiliten formas inéditas de organizaciones colectivas democráticas que no tengan relación alguna con el poder estatal, ni siquiera como objetivo u horizonte de las luchas.

Frente a esa defensa de una emancipación y unos sujetos políticos apostados al margen del Estado, los teóricos del populismo se resisten a abandonar el terreno del Estado democrático liberal, pues eso implicaría para ellos dejarle el campo libre a la derecha neoliberal. No es que la izquierda contemporánea deba abandonar el proyecto emancipatorio sino que debe pensarlo como momento interno de la democracia liberal. Se trata para ellos de llevar adelante una transformación procesual que trunque la articulación neoconservadora entre economía de libre mercado e individualismo posesivo mediante una profundización del momento igualitario de ese liberalismo.

Respecto de los movimientos populares, Laclau aboga por un equilibrio pragmático que evite tanto la excesiva institucionalización, que lleva a la fosilización, como la total falta de articulación, que deriva en impotencia política. Si las organizaciones populares no pueden estar por completo fuera del Estado ni tampoco por completo en el terreno del Estado, urge desde su perspectiva combinar la dimensión horizontal con la dimensión vertical según las exigencias de la coyuntura.

La política populista lejos de tener un carácter de excepción y de remitir necesariamente a la constitución de sujetos emancipadores, designa toda práctica hegemónica que articula y unifica reivindicaciones heterogéneas. Las pequeñas luchas, las conquistas menores, los reclamos que se traducen en leyes, son tan propiamente políticas como las luchas que ponen en jaque el orden vigente. En otras palabras, si una política emancipadora tiene siempre una dimensión populista, no todo populismo tiene un contenido emancipador.

La concepción de Estado que subyace a esta segunda posición es la de un conjunto de ramas y funciones que no conforma un bloque monolítico sino que se caracteriza por relaciones antagónicas entre diferentes centros de poder y por el hecho de que sólo relativamente se encuentra integrado por las prácticas hegemónicas que se desarrollan en su seno. Con la excepción de las burocracias impuestas por la fuerza, el Estado es aquí un campo estratégico con múltiples antagonismos.

En un frente, el Estado aparece como un conjunto de aparatos impermeable a las luchas de las clases populares mientras que sólo resultan auténticamente políticas las luchas y los colectivos totalmente autónomos. Aquí cabría preguntarse si existe un exterior del Estado en el que reina la más absoluta pureza y si esta concepción no es el reverso de la creencia en el Estado como único y definitivo cerco de toda vida política.

En el otro frente, si bien se admite la presencia de focos de resistencia popular en el campo del Estado no se plantea la cuestión decisiva de la transformación de la materialidad institucional y de la política del Estado como momento necesario para que esa presencia (asimétrica respecto del bloque dominante) no termine en un mero gesto discursivo. Al mismo tiempo, desde esta posición resulta difícil pensar formas de democracia de base y de empoderamiento popular más allá del Estado parlamentario.

Por otra parte, si atendemos al proceso de conformación de la práctica política y de los sujetos que actúan en ella, se dibuja una nueva línea de batalla. Mientras que para Laclau, Rancière y Badiou, en cada caso a su modo, la política configura un espacio que se define a sí mismo, que no remite a instancia alguna (ni a la economía, ni a la nación, ni a las clases, ni a la comunidad), para Hardt y Negri no hay sujeto político desarraigado del mundo de la producción.

Respecto de la autonomización de la política cabe preguntarse, ¿no se produce acaso una despolitización de la economía, la cual queda reducida a una práctica exenta de resistencias, mientras que 
las luchas quedan todas ellas encapsuladas en la esfera política? Y en cuanto a la teoría de la multitud inmanente, ¿no tiene lugar un movimiento inverso bajo la forma de una desestimación de la intervención propiamente político-ideológica, de sus operaciones específicas de articulación, interpelación y organización, ejecutada en favor de una cooperación naturalizada entre los trabajadores sometidos de todo el mundo, cuya unidad se presupone, contra todas las evidencias? Para no volverse ilusoria, la cuestión de la emancipación ¿no requiere acaso plantear y pensar las correlaciones de fuerza en la complejidad de la coyuntura?

El dilema nacionalismo/internacionalismo, como vimos, también suscita respuestas heterogéneas. Si bien difieren en las formas (nomadismo, mestizaje, éxodo vs. organización bajo las consignas del comunismo), Hardt y Negri coinciden con Badiou en la premisa de que el nivel de construcción del sujeto emancipador sólo puede ser global; por un lado, para no quedar a merced de las operaciones de contención de los Estados nacionales, por el otro, para poder enfrentar un poder económico que funciona por encima de las fronteras. Rancière si bien acuerda con el diagnóstico de la captación de los Estados por el capital mundializado, no deja de señalar que el proceso de construcción de un pueblo como reclamo igualitario se dirige siempre a un orden de dominación nacional. Laclau, mientras tanto, advierte que la conexión global de las luchas igualitarias como movimiento que tiene por horizonte la emancipación no se puede dar por sentada y pone una vez más el acento en el proceso, de resultado abierto y situado en el espacio de contornos nacionales abierto por la democracia moderna, de unificación de equivalencias en un contexto mundial de multiplicación los antagonismos.

\section{Referencias}

Anderson, Perry (1985). Consideraciones sobre el marxismo occidental. México: Siglo XXI.

Badiou, Alain (1999). El ser y el acontecimiento. Buenos Aires, Argentina: Manantial.

Badiou, Alain (2003). La política a distancia del Estado. Acontecimiento (26), 9-27.

Badiou, Alain (2008a). La teoría del sujeto. Buenos Aires, Argentina: Prometeo.

Badiou, Alain (2008b). ¿Qué representa el nombre de Sarkozy? España: Ellago Ediciones.

Badiou, Alain (2014). Veinticuatro notas sobre los usos de la palabra pueblo. En Badiou, Alain; Bordieu, Pierre; Butler, Judith; Didi-Huberman, Georges; Khiari, Sadri; Rancière, Jacques. ¿Qué es un pueblo? (9-19). Buenos Aires, Argentina: Eterna Cadencia.

Badiou, Alain y Gauchet, Marcel (2015). ¿Qué hacer? Diálogo sobre el comunismo, el capitalismo y el futuro de la democracia. Buenos Aires, Argentina: Edhasa.

Balibar, Étienne (2005). Violencias, identidades, civilidad. Barcelona, España: Gedisa.

Camargo, Ricardo (2014). Repensar lo político. Hacia una nueva política radical. Buenos Aires, Argentina: Prometeo.

Fair, Hernán (2010). El debate político entre los enfoques marxistas, posmarxistas y posmodernos. La Lámpara de Diógenes 11 (20-21). Recuperado de http://www.redalyc.org/src/inicio/ArtPdfRed. jsp?iCve $=84418400016$

González Canosa, Mora (2011). En búsqueda de lo político: algunas notas en torno al pensamiento de Ernesto Laclau y Jaques Rancière. Intersticios. Revista sociológica de pensamiento crítico 5 (2). Recuperado de http://www.intersticios.es.

Guille, Patricio (2017). La constitución de subjetividades políticas en tiempos “post- estatales": un contrapunto entre Agamben, Negri y Laclau. Revista de Humanidades (35). Recuperado de http:// www.redalyc.org/articulo.oa?id=321249925008

Hardt, Michael y Negri, Antonio (2002a). Imperio. Buenos Aires, Argentina: Paidós.

Hardt, Michael y Negri, Antonio (2002b). La multitud contra el imperio. OSAL. Observatorio Social de América Latina (7). Recuperado de http://biblioteca.clacso.edu.ar/clacso/osal/2011021310554 1/11hardtnegri.pd 
Hardt, Michael y Negri, Antonio (2004). Multitud. Guerra y democracia en la era del Imperio. Barcelona, España: Debate.

Hardt, Michael y Negri, Antonio (2009). Commonwealth. El proyecto de una revolución del común. Barcelona, España: Akal.

Harrison, Oliver (2016). Revolutionary Subjectivity in Post-Marxist Thought: Laclau, Negri, Badiou. London, England-New Yok, US: Routledge.

Keucheyan, Razmig (2013). Hemisferio izquierda. Un mapa de los nuevos pensamientos críticos. España: Siglo XXI.

Laclau, Ernesto (2007). La razón populista. Buenos Aires, Argentina: FCE.

Laclau, Ernesto (2008). ¿Puede la inmanencia explicar las luchas sociales? Crítica a Imperio. En Laclau, Ernesto. Debates y combates. Por un nuevo horizonte de la política (125-140). Buenos Aires, Argentina: FCE.

Laclau, Ernesto (2009). Laclau en debate: postmarxismo, populismo, multitud y acontecimiento (entrevistado por Ricardo Camargo). Revista de ciencia política (Santiago) 29 (3). Recuperado de https://dx.doi.org/10.4067/S0718-090X2009000300007

Laclau, Ernesto y Mouffe, Chantal (2015). Hegemonía y estrategia socialista. Hacia una radicalización de la democracia. Buenos Aires, Argentina: FCE.

Marchart, Oliver (2009). El pensamiento político posfundacional. La diferencia política en Nancy, Lefort, Badiou y Laclau. Buenos Aires, Argentina: FCE.

Mouffe, Chantal (1999). El regreso de lo político. Comunidad, ciudadanía, pluralismo, democracia radical. Barcelona, España: Paidós.

Mouffe Chantal (2011). En torno a lo político. Buenos Aires, Argentina: FCE.

Mouffe, Chantal (2012). La paradoja democrática. El peligro del consenso en la política contemporánea. Buenos Aires, Argentina: Gedisa.

Muñoz, María Antonia (2006). Laclau y Rancière: algunas coordenadas para la lectura de lo político. Andamios 2 (4). Recuperado de http://www.scielo.org.mx/scielo. php?script=sci_arttext\&pid=S1870-00632006000100005\&lng=es\&tlng=es.

Negri, Antonio (2001a). Contrapoder. En Fontana, Edgardo; Fontana, Natalia; Gago, Verónica y otros (comp.), Contrapoder. Una introducción (83-95). Buenos Aires, Argentina: Ediciones de mano en mano.

Negri, Antonio (2001b). Entrevista a Toni Negri. Colectivo Situaciones. En Fontana, Edgardo; Fontana, Natalia; Gago, Verónica y otros (comp.), Contrapoder. Una introducción (95-132). Buenos Aires, Argentina: Ediciones de mano en mano.

Negri, Antonio (2007). Goodbye Mr. Socialism: La crisis de la izquierda y los nuevos movimientos revolucionarios. Barcelona, España: Paidós.

Rancière, Jacques (1996). El desacuerdo. Política y filosofía. Buenos Aires, Argentina: Nueva Visión.

Rancière, Jacques (1997). Onze thèses sur la politique. Filozofski vestnik XVIII (2). Recuperado de https://ojs.zrc-sazu.si/filozofski-vestnik/article/view/3995/3704

Rancière, Jacques (24 de enero de 2014). Potencias y problemas de una política del 99\%: entrevista con Jacques Rancière, por Armando Fernando Savater. el diario.es. Recuperado de http://www.eldiario.es/interferencias/Ranciere-politica_del_99_6_221587865.html

Rancière, Jacques y Laclau, Ernesto (8 de mayo de 2015). ¿No nos representan? Discusión sobre Estado y Democracia (reproducción por Fernando Savater del diálogo que tuvo lugar en octubre de 2012 en la Universidad Nacional de San Martín, Buenos Aires, Argentina). eldiario.es. Recuperado de http://www.eldiario.es/interferencias/democracia-representacion-Laclau-Ranciere_6_385721454. html

Rancière, Jacques (7 de febrero de 2016). Cómo salir del odio: entrevista con el filósofo Jacques Rancière por Eric Aeschimann. Le Nouvel Observateur. Recuperado de http://www.eldiario.es/ interferencias/odio-Francia-Ranciere_6_504009609.html 